\title{
Desempenho de Leguminosas Nativas (Adesmia) e Exóticas (Lotus, Trifolium), em Função do Estádio Fenológico no Primeiro Corte ${ }^{1}$
}

\author{
Simone Meredith Scheffer-Basso ${ }^{2}$, Marice Cristine Vendruscolo ${ }^{3}$, Dileta Cecchetti ${ }^{4}$
}

\begin{abstract}
RESUMO - Este trabalho foi desenvolvido com o objetivo de analisar aspectos fenológicos e produtivos de leguminosas nativas (Adesmia latifolia, A. tristis) e exóticas (Lotus corniculatus, L. uliginosus, Trifolium repens), em função do estádio fenológico no primeiro corte: vegetativo (CEV) e florescimento (CEF). As plantas foram estabelecidas em monocultura, no campo, e avaliadas entre maio/2000 e setembro/2001, em Passo Fundo, Rio Grande do Sul. Após o primeiro corte, as plantas foram desfolhadas em intervalos de 45 dias. Foram realizadas nove desfolhações no manejo CEV e sete no CEF. O estádio fenológico no primeiro corte influenciou a produção de massa seca (MS) de . repens $(\mathrm{CEV}=9.000 \mathrm{~kg} / \mathrm{ha}$ de $\mathrm{MS}, \mathrm{CEF}=7.000 \mathrm{~kg} / \mathrm{ha}$ de $\mathrm{MS})$ e A. tristis $(\mathrm{CEV}=4.000 \mathrm{~kg} / \mathrm{ha} \mathrm{de} \mathrm{MS}, \mathrm{CEF}=8.000 \mathrm{~kg} / \mathrm{ha} \mathrm{de}$ MS). O L. corniculatus produziu cerca de $15.000 \mathrm{~kg} / \mathrm{ha}$ de MS e A. latifolia, de 2.000 a $3.000 \mathrm{~kg} / \mathrm{ha}$ de MS, independentemente do manejo. O L. uliginosus não floresceu, produzindo $7.000 \mathrm{~kg} /$ ha de MS no manejo CEV. As espécies nativas mostraram baixa persistência, com morte de plantas (A.tristis) e estolões (A. latifolia) no final da estação de crescimento. A maior produção de $T$. repens foi na primavera e a das espécies de Lotus, no verão.
\end{abstract}

Palavras-chave: cornichão, forragem, persistência, trevo-branco

\section{Performance of Native (Adesmia) and Exotic (Lotus, Trifolium) Legumes as for the Phenological Stage on First-Cutting}

\begin{abstract}
This work had the objective to evaluate phenological and productive aspects of native (Adesmia latifolia, A. tristis) and exotics legumes (Lotus corniculatus, L. uliginosus, Trifolium repens) as for the phenological stage on first-cutting: vegetative (CEV) and flowering (CEF). The plants were established as monoculture in the field and evaluated between May/2000 and September/2001, in Passo Fundo, Rio Grande do Sul. After the first cutting the plants were defoliated in 45 days intervals. There were nine cuttings in CEVmanagement and seven in the CEF-management. The phenological stage on first-cutting modified significantly $(\mathrm{P}<0,05)$ the dry matter (DM) production of $T$. repens $(\mathrm{CEV}=9.000 \mathrm{~kg} / \mathrm{ha}$ of DM, CEF $=7.000 \mathrm{~kg} / \mathrm{ha}$ of DM) and A. tristis $(\mathrm{CEV}=4.000 \mathrm{~kg} / \mathrm{ha}$ of DM, CEF $=8.000 \mathrm{~kg} / \mathrm{ha}$ of DM). L. corniculatus produced about $15.000 \mathrm{~kg} / \mathrm{ha}$ of DM and A. latifolia, 2.000 to $3.000 \mathrm{~kg} / \mathrm{ha}$ of DM, regardless the management. L. uliginosus did not flowered, producing $7.000 \mathrm{~kg} / \mathrm{ha}$ of DM in the CEV-management. The native legumes showed poor persistence with death of the plants (A. tristis) and stolons (A. latifolia) at the end of the growing season. The highest production of the T. repens was in the spring and for the Lotus species, in the summer.
\end{abstract}

Key Words: birdsfoot trefoil, forage, persistence, white clover

\section{Introdução}

Adesmia é um gênero microtérmico, exclusivamente sul-americano, com cerca de 230 espécies. No Brasil, há 17 espécies, das quais 13 ocorrem no Rio Grande do Sul. A. tristis Vog. é considerada uma possível forrageira, enquanto $A$. araujoi Burk. e A. latifolia (Spreng.) Vog. são tidas como ótimas forrageiras (Miotto \& Leitão Filho, 1993). Os estudos têm se intensificado com essas espécies, especialmente A. latifolia e A. tristis. A primeira, por ser estolonífera, e a outra, por ser subarbustiva, o que pressupõe acumular maior quantidade de forragem em relação às espécies herbáceas do gênero. Para ambas, os estudos sobre seu potencial forrageiro ainda estão na fase preliminar, com poucos dados sobre desempenho no campo e, especialmente, comparações com espécies tradicionalmente utilizadas no melhoramento de pastagens naturais, como Lotus e Trifolium. Scheffer-Basso et al. (2001) atestaram o elevado valor nutritivo de $A$. latifolia, com teores de proteína bruta (PB) de até $21,6 \%$ e digestibilidade in vitro da matéria orgânica (DIVMO) de 72,3\%.

No gênero Lotus, o cornichão (L. corniculatus L.) destaca-se por possuir características incomuns à maioria das leguminosas forrageiras, como: pronta

\footnotetext{
1 Parte da dissertação de mestrado da segunda autora.

2 Eng. Agr., Dr., Universidade de Passo Fundo. Cx. Postal 611, Passo Fundo. Cep: 99001-970. Rio Grande do Sul. E.mail: sbasso@ufp.br 3 Eng. Agr.

4 Estatística, MSc., Universidade de Passo Fundo.
} 
formação de gemas adventícias de raízes quando a coroa é removida, vantagem de não causar timpanismo (Smith, 1966), versatilidade de uso (pastejo, feno) e menor exigência de fertilidade de solo em relação a outras leguminosas temperadas. Apesar dessas qualidades, há poucos trabalhos no Brasil, em nível de campo, sobre o seu desempenho sob cortes e nenhum estudo avaliando sua resposta em função do estádio fenológico no primeiro corte. Uma das poucas referências é de Araújo \& Jacques (1974), que, em vasos, obtiveram maior produção de massa seca (MS) em cortes feitos em estádios de crescimento mais avançados. Assim, o seu manejo tem sido feito com base nos trabalhos de Smith (1962) e Nelson \& Smith (1968), realizados nos Estados Unidos. Nesses estudos, as baixas reservas de carboidratos não-estruturais do cornichão durante a estação de crescimento indicaram desfolhações pouco intensas ou a baixas alturas de corte. Segundo Bosworth \& Stringer (2003), o primeiro corte do cornichão, no ano do estabelecimento, deve ocorrer no estádio de florescimento pleno. No caso de estandes já estabelecidos, o primeiro corte pode ser antecipado para o início de florescimento, com seqüência de cortes a cada seis semanas.

Quanto ao L. uliginosus Schkuhr, de hábito rizomatoso, os trabalhos na região sul são mais recentes. $\mathrm{O}$ cv. Maku tem mostrado problemas relativos ao florescimento, restringindo seu cultivo no sul do Basil, em razão da baixa produção de sementes. Essa característica parece estar aliada ao esparso ou, até mesmo, à ausência de florescimento no ano de estabelecimento. Monteiro (1981), na região da Depressão Central do Rio Grande do Sul, observou florescimento tardio, ocorrido somente aos 233 dias após a semeadura. No entanto, é uma espécie que merece a continuidade das avaliações. Na Austrália, o interesse por essa leguminosa aumentou com o reconhecimento de suas características, como: (a) não provocar timpanismo; (b) aumentar a absorção de aminoácidos no rúmen; (c) ser resistente a insetos; (d) possuir habilidade de superar as produções de trevobranco (Trifolium repens L.) em solos com $\mathrm{pH}$ inferior a 5,2; (e) tolerar solos alagados e (f) ser eficiente na absorção de fósforo (Harris et al., 1993).

O trevo-branco é a leguminosa mais utilizada no melhoramento de pastagens naturais, principalmente por sua adaptação ao pastejo intenso. Nas regiões mais frias e com boa distribuição de chuvas, vegeta o ano inteiro. Em regiões mais quentes e sujeitas a estiagens tem seu período de produção reduzido e, em situações extremas, apresenta comportamento de espécie anual, de ressemeadura natural (Paim \& Riboldi, 1994). Como desvantagem, apresenta baixa tolerância a solos ácidos e pobres, como é o caso do sul do Brasil, exigindo correção e adubação para viabilizar seu estabelecimento e sua persistência.

O manejo de leguminosas requer especial atenção, uma vez que afeta sua persistência, tendo-se na alfafa (Medicago sativa L.) o exemplo clássico da importância do estádio fenológico no desempenho agronômico. Aspectos vinculados aos locais de rebrota, aos níveis de reservas de glicídios e à tolerância ao frio, além de afetarem seu desempenho, estão estreitamente vinculados ao estádio de desenvolvimento no primeiro corte, que determina o número de colheitas anuais, sua qualidade e produção total (Starkey et al., 1993).

Este trabalho foi realizado com o objetivo de analisar a fenologia e o desempenho agronômico de leguminosas temperadas nativas (Adesmia) e exóticas (Lotus, Trifolium), em função do estádio fenológico no primeiro corte.

\section{Material e Métodos}

O trabalho foi conduzido entre maio/2000 e setembro/2001, em Passo Fundo, na região fisiográfica do Planalto Médio, Rio Grande do Sul, com coordenadas $28^{\circ} 15^{\prime} \mathrm{S}$ e $52^{\circ} 24^{\prime} \mathrm{W}$ e $687 \mathrm{~m}$ de altitude média. O clima é fundamental úmido, variedade subtropical. $\mathrm{Na}$ Figura 1 constam as informações sobre temperatura e pluviosidade normais da região de Passo Fundo e os dados meteorológicos do período experimental.

O solo da unidade de mapeamento Passo Fundo é classificado como latossolo vermelho-escuro distrófico, com textura argilosa (42\%). No local do experimento, as condições de fertilidade foram as seguintes: $\mathrm{pH}$ $(\mathrm{SMP})=5,8 ; \mathrm{P}=11 \mathrm{mg} / \mathrm{L} ; \mathrm{K}=176 \mathrm{mg} / \mathrm{L} ; \mathrm{Al}=0 \mathrm{cmolc} / \mathrm{L}$; $\mathrm{Ca}=4,1 \mathrm{cmol}_{\mathrm{c}} / \mathrm{L} ; \mathrm{Mg}=3,2 \mathrm{cmol}_{\mathrm{c}} / \mathrm{L}$.

$\mathrm{O}$ ensaio constou da avaliação das seguintes leguminosas: a) Adesmia latifolia: populações Bagé e Lages; A. tristis: populações Lages (acesso BRA 001457) e Painel (acesso BRA 001499); Lotus corniculatus cv. São Gabriel; L. uliginosus cv. Maku; T. repens cv. Ladino Regal. As plantas foram submetidas a dois manejos, caracterizados pelo estádio fenológico no primeiro corte: vegetativo (CEV) e florescimento pleno (CEF). Os tratamentos foram 


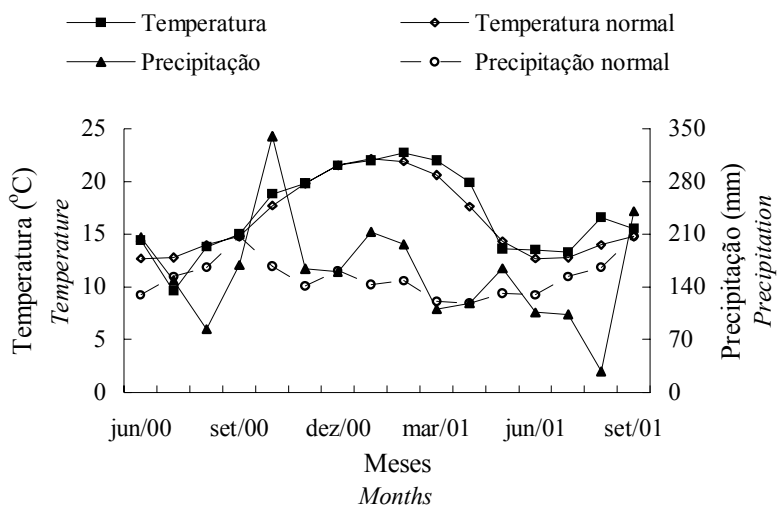

Figura 1 - Temperatura e precipitação médias mensais no período experimental e médias normais (30 anos) em Passo Fundo, RS. (fonte: www.cnpt.embrapa.br).

Figure 1 - Monthly mean temperature and precipitation in the experimental period and the normal means $(30$ years) in Passo Fundo, RS. dispostos em esquema de parcelas subdivididas, sendo alocadas na parcela principal as leguminosas e, nas subparcelas, o manejo de corte. O delineamento experimental foi o de blocos ao acaso, com três repetições. As parcelas principais mediram 2,0 $\mathrm{m}$ de largura por 6,3 $\mathrm{m}$ de comprimento e foram formadas por cinco linhas distantes $0,4 \mathrm{~m}$, com espaçamento entre plantas de $0,3 \mathrm{~m}$, perfazendo um total de 105 plantas/parcela. As subparcelas mediram 2,0 m de largura por 3,15 m de comprimento, com uma área útil de $3,42 \mathrm{~m}^{2}$.

As plântulas foram obtidas por meio de germinação em caixas Gerbox, sendo que, para Adesmia, foi realizada previamente a escarificação em água recém-fervida durante cinco minutos. Após a germinação, as plântulas foram transplantadas para bandejas, onde receberam inoculante pela água de irrigação. Em 22 e 23 de maio de 2000, quando as plântulas estavam com três a quatro folhas, foi realizado o transplante para a área experimental, que havia sido

Tabela 1- Datas das desfolhações em Adesmia, Lotus e Trifolium quanto ao estádio fenológico no primeiro corte Table 1 - Defoliation date in Adesmia, Lotus, Trifolium as for the phenological stage on first-cutting

\begin{tabular}{|c|c|c|c|c|c|}
\hline \multirow[t]{2}{*}{$\begin{array}{l}\text { Estádio fenológico } \\
\text { Phenological stage }\end{array}$} & \multicolumn{5}{|c|}{$\begin{array}{l}\text { Espécie } \\
\text { Specie }\end{array}$} \\
\hline & A. latifolia & A. tristis & L. corniculatus & L. uliginosus & T. repens \\
\hline \multicolumn{6}{|l|}{ Vegetative } \\
\hline $1^{\circ}$ & $23 / 08 / 00$ & $26 / 09 / 00$ & $26 / 09 / 00$ & 26/09/00 & $23 / 08 / 00$ \\
\hline $2^{\mathrm{o}}$ & 07/10/00 & $11 / 11 / 00$ & $11 / 11 / 00$ & $11 / 11 / 00$ & $07 / 10 / 00$ \\
\hline $4^{0}$ & 08/01/01 & $09 / 02 / 01$ & $09 / 02 / 01$ & $09 / 02 / 01$ & 08/01/01 \\
\hline $5^{\circ}$ & $21 / 02 / 01$ & $21 / 03 / 01$ & $21 / 03 / 01$ & $21 / 03 / 01$ & $21 / 02 / 01$ \\
\hline $6^{\circ}$ & $10 / 04 / 01$ & + & $08 / 05 / 01$ & 08/05/01 & $10 / 04 / 01$ \\
\hline $7^{\circ}$ & $25 / 05 / 01$ & + & $22 / 06 / 01$ & $22 / 06 / 01$ & $25 / 05 / 01$ \\
\hline $8^{\circ}$ & 09/07/01 & + & 06/08/01 & 06/08/01 & 09/07/01 \\
\hline $9^{\circ}$ & $24 / 08 / 01$ & + & $24 / 09 / 01$ & $24 / 09 / 01$ & $24 / 08 / 01$ \\
\hline $2^{\circ}$ & $27 / 12 / 00$ & $24 / 01 / 01$ & $07 / 02 / 01$ & $*$ & $27 / 12 / 00$ \\
\hline $3^{\circ}$ & 08/02/01 & 09/03/01 & $21 / 03 / 01$ & $*$ & 08/02/01 \\
\hline $4^{\circ}$ & $21 / 03 / 01$ & + & $08 / 05 / 01$ & $*$ & $21 / 03 / 01$ \\
\hline $5^{\circ}$ & 08/05/01 & + & $22 / 06 / 01$ & $*$ & 08/05/01 \\
\hline $6^{\circ}$ & $22 / 06 / 01$ & + & $06 / 08 / 01$ & $*$ & $22 / 06 / 01$ \\
\hline $7^{0}$ & 06/08/01 & + & $24 / 09 / 01$ & $*$ & 06/08/01 \\
\hline
\end{tabular}

+ estande morto (dead stand); * plantas não floresceram (plants unflowered). 
dessecada com herbicida à base de glifosato. Durante a primeira semana após o plantio, foi feita irrigação manual, assim como a aplicação de iscas e inseticidas para controle de grilos, gafanhotos e formigas. Nas parcelas de $A$. latifolia, após a verificação de falha na nodulação, foi realizada uma aplicação de inoculante por meio de irrigação. Na fase de estabelecimento, as plantas daninhas foram retiradas manualmente. Posteriormente, eliminaram-se apenas as espécies eretas mais evidentes, como guanxuma (Sida sp.) e nabo (Raphanus sp.), mantendo-se espécies rasteiras de dicotiledôneas, como gorga (Spergula arvensis L.) e poaia (Richardia sp.).

As desfolhações foram realizadas a $4 \mathrm{~cm}$ da base das plantas para as espécies prostradas (A. latifolia, trevo-branco, L. uliginosus) e a $8 \mathrm{~cm}$ para as demais. Imediatamente antes dos cortes, foram determinados a altura do dossel e o estádio de fenológico das plantas. A partir do corte inicial, no qual foi imposto o manejo de corte (CEV e CEF), foram realizadas desfolhações a cada 45 dias. Para a decisão do início dos cortes referentes ao estádio vegetativo, escolheuse o trevo-branco como padrão para A. latifolia e o cornichão para as demais. O cronograma das desfolhações encontra-se na Tabela 1.

Os cortes foram realizados na área útil das parcelas com tesouras de esquilar. Após a pesagem do material fresco, foram retiradas amostras para determinação do percentual de matéria seca, por meio de secagem em estufa a $65^{\circ} \mathrm{C}$, até peso constante, com posterior pesagem.

Os dados foram submetidos à análise da variância e a comparação das médias foi realizada pelo teste Tukey a 5\% de significância. Em razão da ausência de florescimento do L. uliginosus e, portanto, não foi submetido a cortes no estádio de florescimento, foi realizada a análise de variância dentro de cada manejo de cortes, enquanto para os dados relativos às demais espécies, a análise de acordo com o esquema de parcela subdividida.

\section{Resultados e Discussão}

Todas as leguminosas floresceram (Tabela 2), com exceção do cv. Maku, que apresentou o mesmo comportamento fenológico observado por SchefferBasso et al. (2002), em casa de vegetação, na mesma região. Esse cultivar tem como característica o florescimento tardio, produzindo poucas flores em latitudes abaixo de $32^{\circ} \mathrm{S}$ (Clarkson et al., 1991), como é o caso da região onde foi realizado este trabalho. A superação desse problema, segundo Paim \& Riboldi (1991), é a seleção de material mais adequado às condições do Rio Grande do Sul. Em contrapartida, o cornichão apresentou três ciclos de florescimento no manejo CEV e dois no CEF, demonstrando maior versatilidade e evidenciando pronta recuperação após os cortes.

A espécie mais precoce foi o trevo-branco, que, por ocasião do segundo corte, no manejo $\mathrm{CEV}$, já estava em florescimento pleno. Essa leguminosa apresentou florescimento longo, estendendo-se até o final do verão. Franke \& Nabinger (1991) também observaram a ocorrência de mais de um ciclo de florescimento em cultivares de trevo-branco na região da Depressão Central, Rio Grande do Sul, com maior concentração de inflorescências entre outubro e janeiro. O intervalo de 45 dias entre cortes foi suficiente para que as plantas de trevo-branco rebrotassem e iniciassem novo ciclo reprodutivo. Segundo Paim \& Riboldi (1994), mesmo com pastejo intenso ou cortes freqüentes, em época de floração intensa, ocorre produção de sementes dessa espécie, pois os estolões estão no nível do solo e entre o surgimento do botão floral e a maturação das sementes são necessários, em períodos quentes, de 20 a 30 dias.

A. latifolia Bagé apresentou maior sincronia de florescimento que as demais espécies, iniciando e finalizando seu ciclo reprodutivo na primavera, especialmente no manejo CEF. A população Lages floresceu novamente no final do verão, embora com menor intensidade em relação ao primeiro ciclo de florescimento. A estacionalidade dos eventos fenológicos observados nessa espécie estão de acordo com os registros de Miotto \& Leitão Filho (1993), que a descreveram como hiberno-primaveril, começando a vegetar no outono, permanecendo verde no inverno e iniciando sua floração em outubro, a qual pode se estender até abril. A sincronia de florescimento observada nessa espécie sugere facilidade no processo de colheita de sementes, ao mesmo tempo que exige manejo criterioso quanto à época de diferimento se o objetivo for a ressemeadura natural.

As populações de $A$. tristis não diferiram quanto ao início da floração (meados da primavera), com comportamento similar ao cornichão. No entanto, sob o manejo $\mathrm{CEV}$, o cornichão frutificou em meados do verão, enquanto, para $A$. tristis, o intervalo de cortes 
Desempenho de Leguminosas Nativas (Adesmia) e Exóticas (Lotus, Trifolium), em Função do Estádio...

Tabela 2 - Comportamento fenológico de Adesmia, Lotus e Trifolium quanto ao estádio fenológico no primeiro corte Table 2 - Adesmia, Lotus and Trifolium phenological behavior as for the phenological stage on first-cutting

\begin{tabular}{|c|c|c|c|c|c|}
\hline \multirow[t]{3}{*}{$\begin{array}{l}\text { Estádio fenológicc } \\
\text { Phenologicalstage }\end{array}$} & \multicolumn{5}{|c|}{$\begin{array}{l}\text { Espécie } \\
\text { Specie }\end{array}$} \\
\hline & Adesmia latifolia & Adesmiatristis & Lotuscorniculatus & Lotusuliginosus & Trifolium repen \\
\hline & Lages & Painel & & & \\
\hline
\end{tabular}

Vegetativo

Vegetative

$1^{\circ}$ (ago/set)

$2^{\circ}$ (out/nov)

$3^{\circ}$ (nov/dez)

$4^{\circ}$ (jan/fev)

$5^{\circ}$ (fev/mar)

$6^{\circ}$ (abr/mai)

$7^{\circ}$ (mai/jun)

$8^{\circ}$ (jul/ago)

$9^{\circ}$ (ago/set)

$\begin{array}{ccc}\text { V } & \text { V } & \text { V } \\ \text { IF } & \text { IF } & \text { IF } \\ \text { FP/FR } & \text { FP/FR } & \text { V } \\ \text { V } & \text { V } & \text { IF } \\ \text { V } & \text { V } & \text { V } \\ \text { V } & \text { V } & - \\ \text { V } & \text { V } & - \\ \text { V } & \text { V } & - \\ \text { V } & \text { V } & -\end{array}$

$\begin{array}{cc}\text { V } & \text { V } \\ \text { IF } & \text { IF } \\ \text { V } & \text { FR } \\ \text { FP } & \text { FP/FR } \\ \text { V } & \text { V } \\ - & \text { V } \\ - & \text { V } \\ - & \text { V } \\ - & \text { V }\end{array}$

$\begin{array}{lc}\text { V } & \text { V } \\ \text { V } & \text { FP } \\ \text { V } & \text { FP } \\ \text { V } & \text { IF } \\ \text { V } & \text { FF/V } \\ \text { V } & \text { V } \\ \text { V } & \text { V } \\ \text { V } & \text { V } \\ \text { V } & \text { V }\end{array}$

Florescimento

Flowering

\begin{tabular}{lccccccc}
\hline $1^{\circ}($ nov/dez $)$ & FP & FP & FP/FR & FP/FR & FP/FR & V & FP \\
$2^{\circ}$ (dez/jan) & $\mathrm{V}$ & $\mathrm{V}$ & FP & FP/FR & FP & V & V \\
$3^{\circ}($ fev/mar $)$ & $\mathrm{V}$ & $\mathrm{V}$ & $\mathrm{V}$ & $\mathrm{V}$ & $\mathrm{V}$ & $\mathrm{V}$ & $\mathrm{V}$ \\
$4^{\circ}(\mathrm{mar} / \mathrm{mai})$ & $\mathrm{V}$ & $\mathrm{IF}$ & - & - & $\mathrm{V}$ & $\mathrm{V}$ \\
$5^{\circ}$ (mai/jun) & $\mathrm{V}$ & $\mathrm{V}$ & - & - & $\mathrm{V}$ & $\mathrm{V}$ \\
$6^{\circ}$ (jun/ago $)$ & $\mathrm{V}$ & $\mathrm{V}$ & - & - & $\mathrm{V}$ & $\mathrm{V}$ & $\mathrm{V}$ \\
$7^{\circ}$ (ago/set $)$ & $\mathrm{V}$ & $\mathrm{V}$ & - & - & $\mathrm{V}$ & $\mathrm{V}$ \\
\hline
\end{tabular}

$\mathrm{IF}=$ início de florescimento, $\mathrm{FF}=$ final do florescimento, $\mathrm{FP}=$ florescimento pleno, $\mathrm{FR}=$ frutificação, $\mathrm{V}=$ vegetativo.

$I F=$ flowering initiation, $F F=$ flowering end,$F P=$ full flowering, $F R=$ fruiting, $V=$ vegetative

não foi suficientemente longo para que as plantas completassem seu ciclo. A população Painel apresentou maior precocidade em relação à Lages, estando em florescimento pleno nos meses de janeiro-fevereiro no manejo CEV. Esse comportamento confirma as observações de Miotto \& Leitão Filho (1993), em estudo taxonômico, que indicaram seu crescimento vegetativo no outono e inverno, com florescimento e frutificação no verão.

Quanto à altura do dossel, as espécies estoloníferas, A. latifolia e trevo-branco, apresentaram as menores alturas, que variaram ao longo do ano, sendo maiores na primavera-verão (Figura 2). Em novembro/2000, o trevo-branco atingiu a maior altura $(28,7 \mathrm{~cm})$ por ocasião do florescimento pleno, quando houve o primeiro corte no manejo CEF; no manejo CEV, a maior altura $(26,6 \mathrm{~cm})$ foi verificada em fevereiro/2001, na quarta desfolhação realizada, quando as plantas estavam no final do florescimento (Tabela 2). A. latifolia também mostrou a maior altura do dossel nessa época, sendo menor que o trevo-branco e variando entre 16,7 (população Bagé) e 19,9 cm (população Lages). Essa diferença interespecífica foi mais evidente sob o manejo CEF, quando o trevo-branco superou $A$. latifolia (população Lages) em $10 \mathrm{~cm}$. Como essas duas espécies são estoloníferas, a estrutura vertical depende basicamente do comprimento das folhas. No trevo-branco, a altura do dossel varia com o alongamento do pecíolo, pois as folhas são trifolioladas; em A. latifolia, a altura depende do alongamento de toda a folha, que é pinada, com vários pares de folíolos ao longo da ráquis. Essas diferenças devem ser consideradas quando da comparação das espécies, pois seguramente devem responder de forma distinta ao sombreamento.

As populações de A. tristis também mostraram variação quanto à altura, sendo que a população Lages, com hábito mais ereto, atingiu $64,8 \mathrm{~cm}$ no manejo CEV e a população Painel, mais prostrada, $47,3 \mathrm{~cm}$. Esses resultados confirmam observações de Scheffer-Basso et al. (2001), nas mesmas populações, sob cultivo em casa de vegetação. No manejo CEF, essas populações atingiram alturas máximas de $93 \mathrm{~cm}$ (Painel) e 121,4 cm (Lages), confirmando a variabilidade intraespecífica para esse caractere. As diferenças de altura verificadas entre os dois manejos 
é atribuída ao hábito subarbustivo dessa leguminosa (Miotto \& Leitão Filho, 1993), expressado apenas nos estádios mais avançados de desenvolvimento.

As espécies de Lotus mantiveram o dossel com altura entre $31,6 \mathrm{~cm}$ (L. uliginosus) e $49 \mathrm{~cm}$ (cornichão), evidenciando a diferença de hábito de crescimento das mesmas. Por ocasião do florescimento pleno, no manejo CEF, o cornichão atingiu $39 \mathrm{~cm}$, aumentando para $49 \mathrm{~cm}$ na rebrota seguinte. Destaca-se que, para ambos os manejos, essa espécie mostrou o maior crescimento vertical em meados do verão, confirmando seu caráter estival (Formoso, 1993). Em geral, todas as leguminosas mostraram sua menor altura nos meses de outono-inverno, com extremos entre 4,6 cm (A. latifolia população Bagé) e $16 \mathrm{~cm}$ (cornichão).

$\mathrm{O}$ manejo de cortes afetou diferentemente as espécies avaliadas, sendo que apenas A. tristis e trevo-branco tiveram seu desempenho alterado signi-
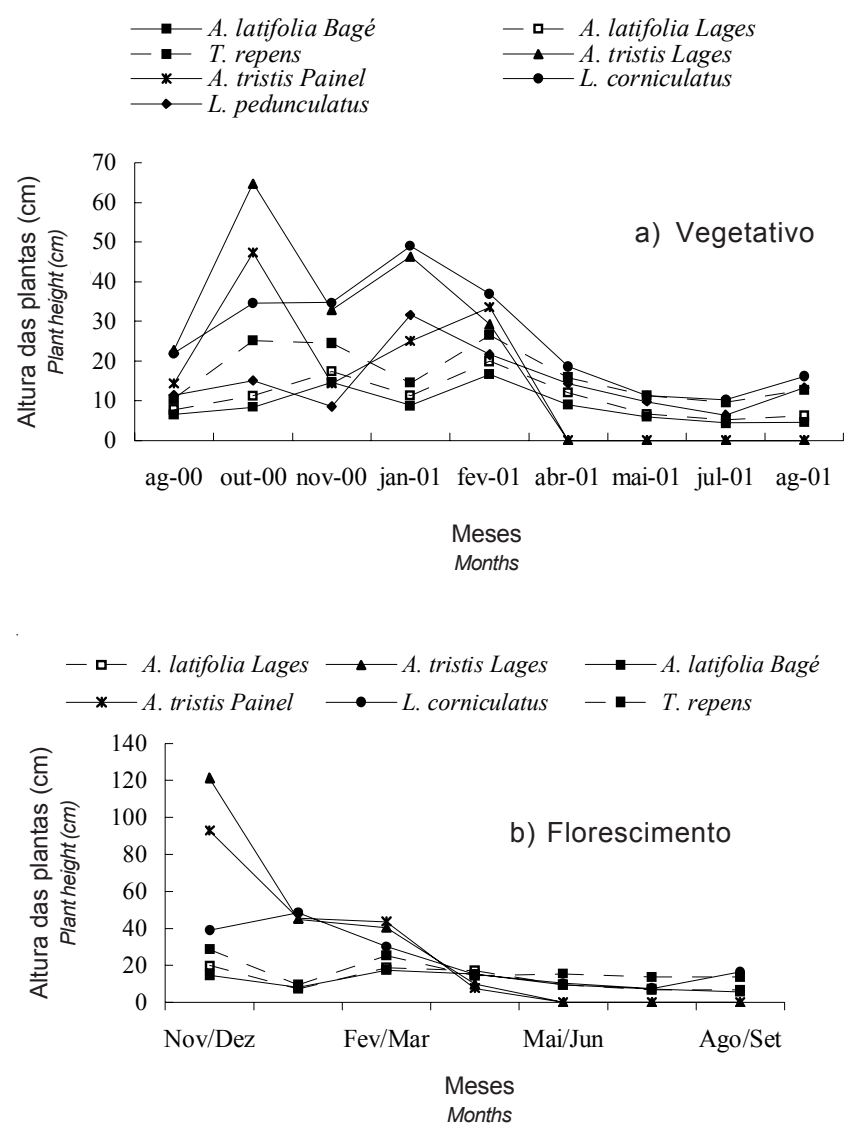

Figura 2 - Altura do dossel de Adesmia, Lotus e Trifolium à época das desfolhações nos manejos vegetativo e florescimento.

Figure 2 - Canopy height of Adesmia, Lotus and Trifolium at the defoliation on the vegetative and flowering management. ficativamente $(\mathrm{P}<0,05)$ pelo estádio fenológico no primeiro corte (Tabela 3 ).

O cornichão se destacou pela maior produção de MS e versatilidade quanto ao manejo de cortes. As produções obtidas foram superiores às verificadas ( $10.000 \mathrm{~kg} /$ ha de MS) por Formoso (1993) e similares às relatadas por Olmos (2001), no Uruguai, e confirmaram sua adaptação à região do Planalto Médio do Rio Grande do Sul (Scheffer-Basso et al., 2002).

O estádio fenológico ao início das desfolhações não influenciou $(\mathrm{P}>0,05)$ o desempenho dessa espécie, havendo compensação da redução do número de cortes (manejo CEF), com maior produção média por corte $(2.044 \mathrm{~kg} /$ ha de MS) em relação ao manejo CEV ( $1.657 \mathrm{~kg} / \mathrm{ha}$ de MS). O adiamento de cerca de 90 dias para o primeiro corte no manejo CEF permitiu um acúmulo adicional de $5.142 \mathrm{~kg} / \mathrm{ha}$ de MS em relação à produção obtida no primeiro corte do manejo CEV (Tabela 4). No entanto, as produções de MS obtidas nas três primeiras colheitas do manejo CEV totalizaram $6.224 \mathrm{~kg} /$ ha de MS, muito similar ao obtido em umúnico corte, no manejo CEF (6.095 kg/ha de MS), evidenciando diferentes possibilidades de manejo. Isso sugere a pequena perda de material verde na espécie com o adiamento do início das colheitas, que pode ser atribuído parcialmente ao seu hábito de crescimento ereto, que condiciona boa penetração da luz.

Tabela 3 - Produção total de massa seca (kg/ha de MS) de Adesmia, Lotus e Trifolium quanto ao estádio fenológico no primeiro corte

Table 3 - Total dry matter yield ( $\mathrm{kg} / \mathrm{ha}$ of DM) of Adesmia, Lotus and Trifolium as for the phenological stage on first-cutting

\begin{tabular}{lc}
\hline Espécie & Estádio fenológico \\
Specie & Phenological stage
\end{tabular}

Specie Phenological stage

\begin{tabular}{lcc}
\cline { 2 - 3 } & $\begin{array}{c}\text { Vegetativo } \\
\text { Vegetative }\end{array}$ & $\begin{array}{c}\text { Florescimento } \\
\text { Flowering }\end{array}$ \\
\hline \multicolumn{2}{c}{ MS (kg/ha) } \\
DM (kg/ha)
\end{tabular}

Médias seguidas de letras iguais, minúsculas nas colunas e maiúsculas nas linhas, não diferem $(P>0,05)$ pelo teste Tukey. Means followed by the same letter, small in the columns and capital in the rows, do not differ $(P>0.05)$ by Tukey test. 
Apesar da similaridade nas produções nos dois manejos de corte, observou-se maior uniformidade quando se iniciaram os cortes no estádio vegetativo (Tabela 4). Nesse manejo, $80 \%$ da produção total do cornichão foi dividida entre quatro cortes, entre outubro e março. Com o manejo CEF, $77 \%$ da produção foi obtida em dois cortes, entre final de dezembro e início de fevereiro. Formoso (1993) também relatou esse comportamento, no Uruguai, onde, com o aumento da idade, o cv. São Gabriel concentrou cada vez mais sua produção na primavera-verão.

Pelos dados obtidos, se confirma a versatilidade do cornichão quanto às possibilidades de utilização: pastejo, feno, produção de sementes ou banco de proteína. Em situação de pastejo, sua utilização pode- ria iniciar antes do florescimento, ao passo que, para feno, o primeiro corte poderia ocorrer no florescimento pleno, sendo possível dois cortes, com elevadas produções no período estival. McGraw \& Marten (1986) obtiveram cerca de $7.000 \mathrm{~kg} / \mathrm{ha}$ de MS de cornichão no estádio de florescimento pleno. Os resultados obtidos neste trabalho confirmam as indicações de Seaney \& Henson (1970) de que é possível duas a três colheitas de cornichão para a produção de feno, dependendo da extensão da estação de crescimento. No manejo CEF, obteve-se ainda ótima produção do cornichão no terceiro corte $(2.117 \mathrm{~kg} / \mathrm{ha}$ de $\mathrm{MS})$, quando já era final do verão. As baixas produções das rebrotas de inverno atestaram o caráter macrotérmico dessa espécie, evidenciado por Formoso (1993), no

Tabela 4 - Produção mensal de massa seca (kg/ha de MS) de Adesmia latifolia (AL), Lotus corniculatus (LC), L. uliginosus (LU) e Trifolium repens (TR) quanto ao estádio fenológico no primeiro corte (vegetativo/florescimento)

Table 4 - Adesmia latifolia (AL), Lotus corniculatus (LC), L. uliginosus (LU) and Trifolium repens (TR) monthly dry matter yield ( $\mathrm{kg} / \mathrm{ha}$ of $\mathrm{DM})$ as for the phenological stage on first-cutting (vegetative/ flowering)

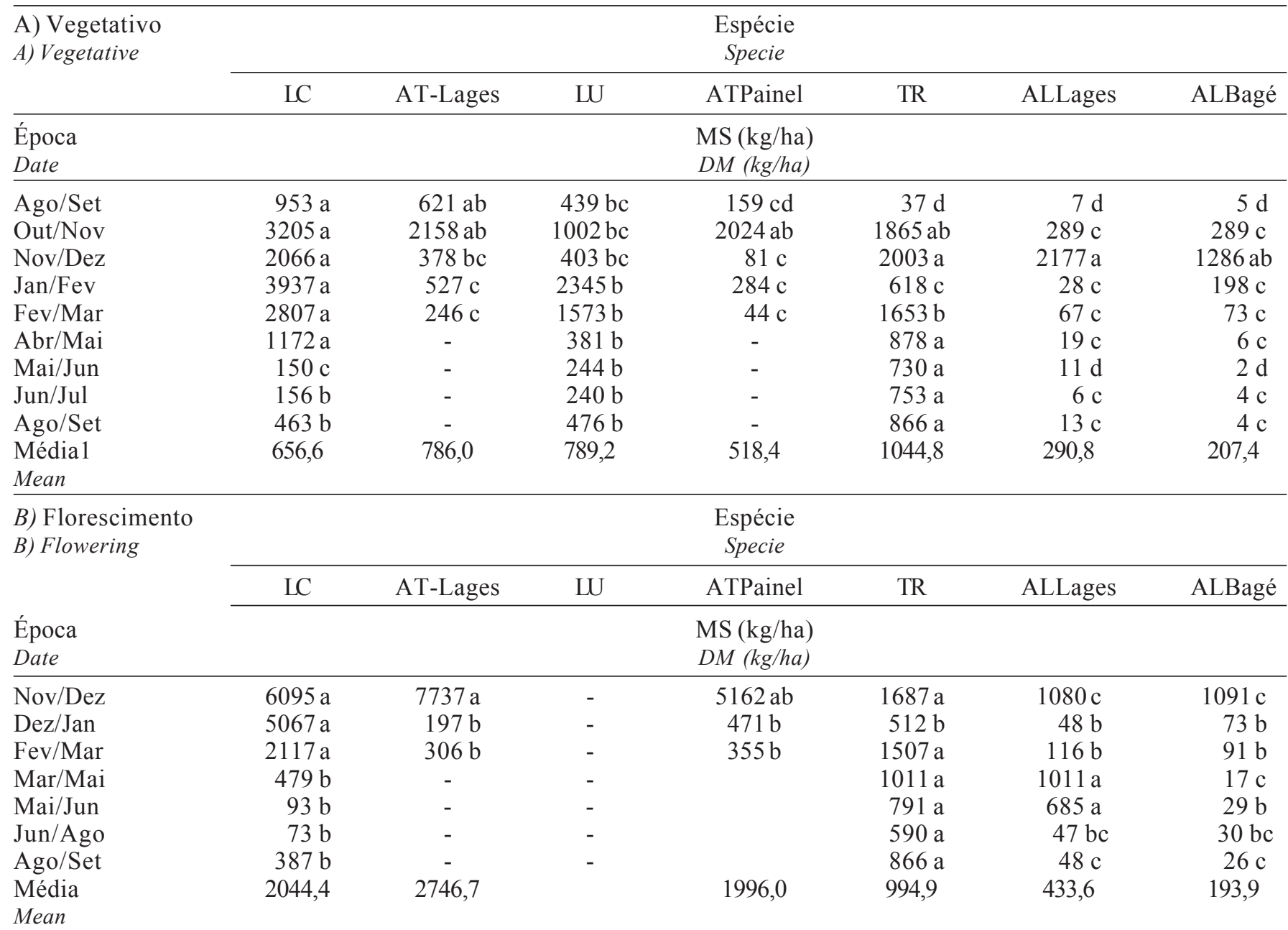

Dentro do estádio fenológico (vegetativo/florescimento), médias seguidas de mesma letra, na coluna, não diferem (P>0,05) pelo teste Tukey.

Within phenological stage (vegetative/flowering), means followed by the same letter, in the column, do not differ (P>0.05) by Tukey test. 
Uruguai, e por Scheffer-Basso et al. (2002), no Rio Grande do Sul.

Juntamente com o cornichão, o trevo-branco foi a espécie com melhor desempenho (Tabela 3), como reflexo da domesticação e dos esforços nas pesquisas com essas leguminosas nas últimas décadas. No entanto, ao contrário do cornichão, o trevo-branco não mostrou a mesma compensação entre as produções de MS nos dois manejos adotados. Obteve-se maior $(\mathrm{P}<0,05)$ produção de forragem dessa espécie no manejo CEV (+35\%) que no CEF (Tabela 2), atribuído ao maior número de cortes realizados com esse manejo, uma vez que a produção média/corte foi muito similar nos dois manejos, $1.041 \mathrm{~kg} / \mathrm{ha}$ de MS (CEV) e $995 \mathrm{~kg} / \mathrm{ha}$ de MS (CEF). Na soma da massa seca colhida nos três primeiros cortes do manejo CEV, obteve-se $3.905 \mathrm{~kg} / \mathrm{ha}$ de MS, em um período de tempo similar ao do primeiro corte no manejo CEF, com apenas $1.687 \mathrm{~kg} /$ ha de MS (Tabela 4).

Portanto, há vantagem em se iniciar a utilização dessa espécie no estádio vegetativo, uma vez que as rebrotas posteriores não são prejudicadas. Considerando-se que houve um intervalo de aproximadamente 90 dias entre o início dos cortes nos dois manejos e que, nesse mesmo período, foi possível efetuar três cortes no manejo CEV, deixou-se de colher $2.218 \mathrm{~kg} / \mathrm{ha}$ de MS pelo simples adiamento da desfolhação. Essa perda de massa pode ser creditada ao hábito de crescimento da espécie, que depende da ramificação dos estolões para formar novas folhas. Com o crescimento excessivo, que ultrapassa o índice de área foliar ótimo, o sombreamento limita a ativação das gemas e, portanto, a ramificação dos estolões e o surgimento de novas folhas. Segundo Thompson (1993), o crescimento de plantas de trevo-branco sob sombreamento produz baixa proporção de ramificações nos nós, com poucas folhas por ramos e maiores entrenós e pecíolos que plantas não sombreadas.

As produções obtidas com o L. uliginosus cv. Maku foram similares às obtidas $(6.133 \mathrm{~kg} /$ ha de MS) por Olmos (2001), no Uruguai, em semeadura sobre campo nativo, e superiores às relatadas $(2.828 \mathrm{~kg} / \mathrm{ha}$ de MS) por Flaresso \& Almeida (1992), no Vale do Itajaí (SC), atestando diferenças ambientais e de manejo. Em mistura com festuca (Festuca arundinacea Schreb), em Passo Fundo, SchefferBasso et al. (2002) obtiveram $1.400 \mathrm{~kg} / \mathrm{ha}$ de MS desse cultivar no outono e $760 \mathrm{~kg} / \mathrm{ha}$ de MS no inverno. Verificou-se que a produção de MS foi concentrada entre outubro e março, com pico de crescimento em fevereiro (Tabela 4), o que é altamente desejável, pois, no sul do Brasil, essa é uma época crítica em termos de quantidade e qualidade de forragem. A introdução de Lotus nos campos nativos ou pastagens perenes implantadas pode melhorar a dieta dos animais em uma época crítica, como é o final do verão, o que já foi constatado por Bemhaja \& Risso (1998), no Uruguai.

Quanto ao desempenho das leguminosas nativas, observou-se diferença $(\mathrm{P}<0,05)$ entre os manejos de cortes apenas para $A$. tristis, que dobrou sua produção sob o manejo CEF, o que é atribuído ao hábito subarbustivo, somente definido no estádio de florescimento. No entanto, a utilização tardia de A. tristis tem o ônus da redução da qualidade da forragem, pelo aumento proporcional de caules. Dados de Scheffer-Basso et al. (2001) indicaram percentuais de DIVMO muito baixos (35 a 44\%) para os caules dessa espécie. Essas informações, aliadas à escassa rebrota (Tabela 4), restringem seu valor como planta forrageira e desestimulam a continuidade dos trabalhos para esse fim.

A. latifolia não teve seu desempenho afetado em função do manejo de corte, indicando um modelo diferenciado de crescimento em relação ao trevobranco e que merece ser investigado. Entre as populações de $A$. latifolia, a Lages mostrou maior produção, especialmente no manejo $\mathrm{CEF}$, principalmente em razão da melhor rebrota no final do verão, quando foi similar ao trevo-branco. Essa população diferiu da outra, por exibir maior altura (Figura 2) e apresentar dois picos produtivos (Tabela 4 ).

Comparando-se a expansão lateral do trevo-branco e a da $A$. latifolia, verificou-se que $A$. latifolia teve maior capacidade de exploração da superfície, em nível de distância percorrida pelos estolões, explicado pelo seu maior comprimento de entrenó (Favero et al., 2002), o que facilita o deslocamento e a ocupação de novos sítios. O trevo-branco, por sua vez, tem entrenós curtos, adquirindo forma mais compacta e com maior potencial de formação de folhas e entrenós em uma mesma área. Essas diferenças de estratégias de crescimento podem explicar as diferenças de produção e persistência entre essas espécies. Observou-se, neste estudo, deslocamento espacial do dossel $A$. latifolia, com desaparecimento quase total das plantas no local de plantio, em comportamento similar ao de uma planta anual. Ao longo do tempo, o dossel se 
distanciou do local de plantio, abrangendo os caminhos e as áreas externas do ensaio.

Em uma contagem de estolões (dados não apresentados) à época do segundo corte, no manejo CEV, as plantas de A. latifolia apresentaram cerca de 125 estolões $/ 0,24 \mathrm{~m}^{2}$, superior ao trevo-branco (91 estolões/ $\left.0,24 \mathrm{~m}^{2}\right)$. No entanto, no início do outono (março/01), o trevo-branco apresentava 140 estolões $/ 0,24 \mathrm{~m}^{2}$, enquanto $A$. latifolia apenas 17 estolões $/ 0,24 \mathrm{~m}^{2}$. Essa alteração demográfica no número de estolões pode explicar a baixa produção dessa leguminosa, corroborando com informações de outros autores. Segundo Miotto \& Leitão Filho (1993), sua ocorrência é esporádica, às vezes luxuriante ou quase nula. Burkart (1952) também a descreveu como "viajante", indicando seu caráter exploratório.

O comportamento demográfico de A. latifolia sugere, a princípio, a necessidade do diferimento à época do florescimento, para que ocorra a ressemeadura natural e, dessa forma, seja obtida a persistência da espécie na pastagem por meio de novas plântulas. No entanto, é importante que sejam realizados estudos sobre seu modelo de crescimento clonal. Nesse aspecto, Kroon \& Schieving (1990) definem três estratégias de crescimento clonal, caracterizadas como mecanismos por: a) busca por recursos (foraging growth); b) eficiente utilização de recursos (conservative growth); e c) monopolização de recursos disponíveis no tempo e no espaço (consolidation growth). A definição da estratégia de crescimento da espécie pode auxiliar nos trabalhos de estabelecimento e manejo em áreas de pastagens.

Finalmente, é importante salientar que os resultados aqui relatados se referem à produção de primeiro ano, devendo ser analisados como indicativos do comportamento das leguminosas ao manejo estudado e como subsídio a futuros estudos, especialmente com as espécies nativas, para as quais as informações são restritas.

\section{Conclusões}

O desempenho produtivo e a persistência das espécies exóticas e domesticadas - Lotus corniculatus, L. uliginosus e Trifolium repens são superiores aos das espécies nativas e silvestres Adesmia latifolia e $A$. tristis.

Trifolium repens apresenta melhor desempenho sob desfolhações iniciadas no estádio vegetativo.
L. corniculatus apresenta versatilidade quanto ao manejo, com produções anuais similares sob desfolhações iniciadas no estádio vegetativo ou no florescimento, havendo, no entanto, alteração na distribuição da produção anual, com maior concentração no verão, quando o primeiro corte ocorre no florescimento.

A. tristis produz maior quantidade de massa seca quando o primeiro corte é efetuado no florescimento. No entanto, sua fraca rebrota, independentemente do manejo imposto, limita seu valor como planta forrageira. A. latifolia apresenta versatilidade quanto ao estádio fenológico no primeiro corte, mas seu comportamento demográfico deve ser estudado, para indicações seguras quanto ao estabelecimento e manejo.

\section{Literatura Citada}

ARAÚJO, J.C.; JACQUES, A.V.A. Características morfológicas e produção de matéria seca do cornichão (Lotus corniculatus L.) colhido em diferentes estádios de crescimento e a duas alturas de corte. Revista Brasileira de Zootecnia, v.3, n.2, p.138-47,1974.

BEMHAJA, M.; RISSO, D.F. Establecimiento y producción de Lotus pedunculatus cv. Maku em três comunidades nativas sobre suelos del area ganadera del Uruguay. In: REUNIÃO DO GRUPO TÉCNICO EM FORRAGEIRAS DO CONE SUL ZONA CAMPOS, XVII - Utilização sustentável e melhoramento de campos naturais do Cone Sul: desafios para o III milênio. Anais... Lages: Epagri-UDESC, 1998. p.152.

BOSWORTH, S.C.; STRINGER, W.C. Cutting management of alfalfa, red clover, and birdsfoot trefoil. Disponível em: http:/ /www.agronomy.psu.edu. Acessado em: 16/03/2003.

BURKART, A. Las leguminosas argentinas silvestres y cultivadas. Buenos Aires: ACME Agency, 1952. 569p.

CLARKSON, N.M.; MEARS, P.T.; LOWE, K.F. et al. Sustaining productive in the tropics. 8 . Persistence and productivity of temperate legumes with tropical grasses. Tropical Grasslands, v. 25, p.129-136, 1991.

FAVERO, D.; SCHEFFER-BASSO, S.M.; FIORESE, I. et al. Tolerância de Adesmia latifolia e Trifolium repens ao alumínio. In: MOSTRA DE INICIAÇÃO CIENTÍFICA DA UNIVERSIDADE DE PASSO FUNDO, 12., 2002, Passo Fundo. Anais... Passo Fundo: Universidade de Passo Fundo, 2002. CD-ROM.

FLARESSO, J.A.; ALMEIDA, E.X. Introdução e avaliação de forrageiras temperadas no alto vale do Itajaí, Santa Catarina. Revista Brasileira de Zootecnia, v.21, n.2, p.309-319, 1992.

FORMOSO, F. Lotus corniculatus L.: Performance forrajera y características agronómicas asociadas. Montevideo: INIA, 1993. 20p. (Boletin de divulgación, 37)

FRANKE, L.B.; NABINGER, C. Dinâmica do florescimento de cinco cultivares de trevo-branco. Pesquisa Agropecuária Brasileira, v.26, n.9, p.1475-85, 1991.

HARRIS, C.A.; BLUMENTHAL, M.J.; SCOOT, J.M. Survey of use and management of Lotus pedunculatus cv. Grasslands 
Maku in eastern Australia. Australian Journal of Experimental Agriculture, v.33, n.1, p.41-47, 1993.

KROON, H.; SCHIVING, F. Resource partitioning in relation to clonal growth strategy. In: GROENENDAEL, J.; KROON, $\mathrm{H}$. (Eds.) Clonal growth in plants: regulation and function. The Hague: Academic Publishing, 1990. p.113-130.

McGRAW, R.L.; MARTEN, G.C. Analysis of primary spring growth of four pasture legume species. Agronomy Journal, v.78, p.704-710, 1986.

MIOTTO, S.T.S.; LEITÃO FILHO, H.F. Leguminosae-Faboideae - Gênero Adesmia DC. Boletim do Instituto de Biociências, n.52, p.1-157, 1993.

MONTEIRO, I.D. Teste de progênie de policruzamento de Lotus uliginosus Schkuhr. Porto Alegre: Universidade Federal do Rio Grande do Sul, 1981. 118p. Dissertação (Mestrado em Zootecnia) - Universidade Federal do Rio Grande do Sul, 1981.

NELSON, C.J.; SMITH, D. Growth of birdsfoot trefoil and alfafa. II. Morfological development and dry matter distribution. Crop Science, v.8, p.21-25, 1968.

OLMOS, F.O. Mejoramiento de pasturas con Lotus en la región noreste. Montevideo: INIA. 2001. 48p. (Série Técnica, 124)

PAIM, N.R.; RIBOLDI, J. Competição entre espécies e cultivares do gênero Lotus L. Pesquisa Agropecuária Brasileira, v.26, n.10, p.1699-1704, 1991.

PAIM, N.R.; RIBOLDI, J. Duas novas cultivares de trevo-branco comparadas com outras disponíveis no Rio Grande do Sul, em associação com gramíneas. Pesquisa Agropecuária Brasileira, v.29, n.1, p.43-53, 1994.
SCHEFFER-BASSO, S.M.; JACQUES, A.V.A.; DALL'AGNOL, M. et al. Disponibilidade e valor nutritivo de forragem de leguminosas nativas (Adesmia DC.) e exóticas (Lotus L.). Revista Brasileira de Zootecnia, v.30, n.3, p.975-982, 2001.

SCHEFFER-BASSO, S.M.; VENDRUSCOLO, M.C.; BARÉA, K. et al. Comportamento de leguminosas (Adesmia, Lotus, Trifolium) em mistura com festuca (Festuca arundinacea Schreb.). Revista Brasileira de Zootecnia, v.31, n.6, p. 2197 2203, 2002.

SEANEY, R.R.; HENSON. P.R. Birdsfoot trefoil. Advances in Agronomy, v.22, p.119-157, 1970.

SMITH, D. Carbohydrate root reserves in alfafa, red clover, and birdsfoot trefoil under several management schedules. Crop Science, v.2, p.75-78, 1962.

SMITH, D. The unusual growth responses of birdsfoot trefoil. Crop \& Soils, v.18, n.7, p.12, 1966.

STARKEY, D.L.; SHROYER, J.P.; FICK, W.H. et al. Effects of early-cutting management on forage yield and quality of alfalfa in northeast Kansas. Keeping up with research, 105. 1993. $6 \mathrm{p}$.

THOMPSON, L. The influence of the radiation environment around the node on morphogenesis and growth of white clover (Trifolium repens). Grassland and Forage Science, v.48, p.271-8, 1993.

Recebido em: 29/03/04

Aceito em: 14/06/05 